\title{
Growth of embryo and gene expression of nutrient transporters in the small intestine of the domestic pigeon (Columba livia) ${ }^{*}$
}

\author{
Ming-xia $\mathrm{CHEN}^{\S 1}$, Xiang-guang $\mathrm{LI}^{\S 1}$, Jun-xian $\mathrm{YANG}^{1}$, Chun-qi GAO ${ }^{1}$, \\ Bin $W_{A N G}^{2}$, Xiu-qi WANG ${ }^{\dagger 1}$, Hui-chao YAN ${ }^{\dagger 1}$ \\ ( ${ }^{1}$ College of Animal Science, South China Agricultural University / Key Laboratory of Chicken Genetics, Breeding and Reproduction, \\ Ministry of Agriculture / Guangdong Provincial Key Laboratory of Agro-Animal Genomics / South China Collaborative Innovation \\ Center for Poultry Disease Control and Product Safety, Guangzhou 510642, China) \\ ( ${ }^{2}$ Guangdong Fengli Agricultural Comprehensive Development Co., Ltd., Maoming 525000, China) \\ †E-mail: xqwang@scau.edu.cn; yanhc@scau.edu.cn \\ Received Nov. 30, 2014; Revision accepted Mar. 18, 2015; Crosschecked May 13, 2015
}

\begin{abstract}
The objective of this study was to investigate the relationship between gene expression of nutrient (amino acid, peptide, sodium and proton) transporters in the small intestine and embryonic growth in domestic pigeons (Columba livia). One hundred and twenty-five fertilized eggs were randomly assigned into five groups and were incubated under optimal conditions (temperature of $38.1{ }^{\circ} \mathrm{C}$ and relative humidity of $55 \%$ ). Twenty embryos/birds from each group were sacrificed by cervical dislocation on embryonic day (E) 9, 11, 13, 15 and day of hatch (DOH). The eggs, embryos (without yolk sac), and organs (head, brain, heart, liver, lungs, kidney, gizzard, small intestine, legs, and thorax) were dissected, cleaned, and weighed. Small intestine samples were collected for RNA isolation. The mRNA abundance of intestinal nutrient transporters was evaluated by real-time reverse transcription-polymerase chain reaction (RT-PCR). We classified these ten organs into four types according to the changes in relative weight during embryonic development. In addition, the gene expression of nutrient transporters was differentially regulated by embryonic day. The mRNA abundances of $b^{0,+} A T, E A A T 3, y^{+} L A T 2, P e p T 1$, LAT4, NHE2, and NHE3 increased linearly with age, whereas mRNA abundances of CAT1, CAT2, LAT1, EAAT2, SNAT1, and SNAT2 were increased to higher levels on $\mathrm{E} 9$ or $\mathrm{E} 11$ and then decreased to lower levels until $\mathrm{DOH}$. The results of correlation analysis showed that the gene expressions of $b^{0,+} A T, E A A T 3, P e p T 1, L A T 4, N H E 2, N H E 3$, and $y^{+} L A T 2$ had positive correlations with body weight $(0.71<$ correlation coefficient $(C C)<0.82, P<0.0001)$, while CAT1, CAT2, EAAT2, SNAT1, and SNAT2 had negative correlations with body weight $(-0.86<C C<-0.64, P<0.0001)$. The gene expressions of $b^{0,+} A T, E A A T 3, L A T 4$, PepT1, NHE2, NHE3, and $y^{+} L A T 2$ showed positive correlations with intestinal weight $(0.80<C C<0.91, P<0.0001)$, while CAT1, CAT2, and EAAT2 showed negative correlations with intestinal weight $(-0.84<C C<-0.67, P<0.0001)$. It was concluded that the differences between growth trajectories of organs and gene expression of nutrient transporters in small intestine were due to their functional and physiological properties, which provided a comprehensive study of amino acid and peptide transporter mRNA in the small intestine during embryonic growth of pigeons.
\end{abstract}

Key words: Embryonic growth, Nutrient transporters, Gene expression, Small intestine, Pigeons doi: 10.1631 jzus.B1400340

\section{Introduction}

\footnotetext{
Corresponding authors

${ }^{\S}$ The two authors contributed equally to this work

* Project supported by the Spark Program of Guangdong, China (No. 2012A020603012)

(D) ORCID: Xiu-qi WANG, http://orcid.org/0000-0003-2033-9485

(C) Zhejiang University and Springer-Verlag Berlin Heidelberg 2015
}

Embryonic growth in precocial birds has been widely investigated, for instance duck (Tangara et al., 2010), turkey (Stepińska et al., 2012), and chicken (Li et al., 2014). In contrast to precocial poultry, young pigeons, a typical representative of altricial birds, are 
feed with pigeon milk from the crop by parents for a few days. However, there is limited information available on the development of embryo and organs in this species.

The embryonic growth and development in poultry not only directly affect the embryonic quality and hatchability, but also affect the ontogeny of the young after hatch. Unlike mammals, avian embryo development is dependent upon the finite nutrient deposits in the fertile egg (Finkler et al., 1998). Embryonic development of chicks is divided into three phases. At the first third of incubation (first week of incubation), the germ, chorionic sac, and allantoic cavity are established. Embryo completion is formed through the second third (from Day 8 to Day14), and the embryo development is prepared for emergence and hatching in the final stage of incubation (from Day 15 to the day of hatch (DOH)) (Moran, 2007). In the last 2 to $3 \mathrm{~d}$ of incubation, the residual yolk, as a nutritional source, reaches the small intestine via the yolk stalk (Noy and Sklan, 1998). Therefore, the embryo would impair absorption of nutrients from the yolk sac, and then nutrient absorption occurs primarily through the small intestine close to hatch (Noy et al., 1996; Speier et al., 2012). Thus, it is necessary to understand the development patterns of intestinal absorptive capacity because of its key function in nutrient intake.

In the small intestine, the absorption of nutrients is mediated by transporter proteins expressed in the enterocyte. The nutrient passed through the epithelium of the small intestine and into the blood stream via special transporters. According to Poncet and Taylor (2013), different nutrient transporters have different gene expression patterns and functions. For example, amino acids are transported into the intestinal epithelial cells as di- or tri-peptides by the $\mathrm{H}^{+}$-dependent peptide transporter 1, PepT1 (Leibach and Ganapathy, 1996) or a variety of amino acid transporters that have specificity for anionic, cationic, or neutral amino acids (Hyde et al., 2003). Most of the studies are focused on the gene expressions of intestine nutrient transporters in precocial poultry, such as chicken (Mott et al., 2008; Sun et al., 2015; Miska et al., 2014) and turkey (de Oliveira et al., 2009). Our laboratory has studied gene expressions of cationic and neutral amino acid (Zeng et al., 2011), excitatory amino acid (Li et al., 2011), small peptide, and sodium and proton (Li et al., 2012) transporters in the small intestine of chick embryos. Furthermore, these studies found that the expression levels of the $b^{0,+} A T$, $E A A T 3$, and PepT1 in the small intestine had strong correlations with chick embryo development, which could be used as indicators for the chick embryo growth of the small intestine (Li et al., 2013). The gene expression level of intestinal fatty acid (Xie et al., 2012; 2013) and sodium glucose (Dong et al., $2012 \mathrm{~b}$ ) transporters in pigeons, and the activity of digestive enzyme in pigeon yolk sac membrane during pre- and post-hatch development have been reported (Dong et al., 2012a). However, the underlying relationship of embryonic growth and gene expression of nutrient transporters in the small intestine has not been evaluated in pigeons. Therefore, the objective of this study was to investigate: (1) the growth of embryo and organs in the stage of embryonic development and (2) the underlying relationship between gene expression of nutrient (amino acid, peptide, sodium and proton) transporters in the small intestine and embryonic growth of pigeons.

\section{Materials and methods}

All experimental methods and management procedures were approved by the Animal Care Committee of South China Agricultural University (Guangzhou, China).

\subsection{Experimental design and sample collection}

A total of 125 fertilized pigeon (Columba livia) eggs were obtained from Brother Economic Development Co. Ltd. (Guangdong, China). Eggs were weighed $((21.08 \pm 0.12) \mathrm{g})$ and randomly assigned into five groups. The egg weights in each group did not show a significant difference $(P>0.90)$. The eggs were then incubated at $38.1{ }^{\circ} \mathrm{C}$ and $55 \%$ relative humidity in an incubator (Keyu, Guangzhou, China). At embryonic day (E) 7 of incubation, all the eggs were candled for the detection of unfertilized eggs; these were removed from the incubator. On E9, E11, E13, E15, and DOH, the eggs were opened and embryos/birds were freed from the allantois and yolk. At any given age, twenty embryos/birds from each group were sacrificed by cervical dislocation. The eggs, embryos (without yolk sac), and organs (head, brain, heart, liver, lung, kidney, gizzard, small 
intestine, leg, and thorax) were dissected, lightly blotted and drained of blood or any fluid contents with phosphate-buffered saline $(\mathrm{NaCl}, 8 \mathrm{~g} / \mathrm{L} ; \mathrm{KCl}, 0.2 \mathrm{~g} / \mathrm{L}$; $\mathrm{Na}_{2} \mathrm{HPO}_{4}, 1.42 \mathrm{~g} / \mathrm{L} ; \mathrm{KH}_{2} \mathrm{PO}_{4}, 0.27 \mathrm{~g} / \mathrm{L}$ ) at $4{ }^{\circ} \mathrm{C}$, and weighed. All of the small intestine samples were placed in $0.5-\mathrm{ml}$ microcentrifuge tubes, frozen in liquid nitrogen, and stored at $-80{ }^{\circ} \mathrm{C}$ for mRNA analysis.

\subsection{Total RNA isolation and cDNA synthesis}

The total RNA was isolated from the small intestine tissue of pigeon embryos using TRIzol Reagent (Invitrogen, Carlsbad, USA) according to the manufacturer's instructions. The RNA quality was checked by $1.5 \%$ agarose gel electrophoresis, stained with $10 \mu \mathrm{g} / \mathrm{ml}$ ethidium bromide. The optical density (OD) of the RNA was measured by a NanoDrop 2000 UV-Vis spectrophotometer (Thermo, Wilmington, MA, USA) and $\mathrm{OD}_{260} / \mathrm{OD}_{280}$ ratio was between 1.8 and 2.0. Reverse transcription (RT) reaction mixtures $(20 \mu \mathrm{l})$ comprised $2 \mu \mathrm{g}$ of total RNA, N10 primers (Sangon, Shanghai, China), M-MLV reverse transcriptase (Promega, Madison, USA), RNase inhibitor (TaKaRa, Shiga, Japan), and dNTP. The complementary DNA (cDNA) products were diluted 1:3 using DEPC water and stored at $20^{\circ} \mathrm{C}$ for quantitative realtime polymerase chain reaction (qRT-PCR) analysis.

\subsection{Quantification of mRNA by qRT-PCR}

The abundance of mRNA was measured by qRT-PCR with a Stratagene MxPro 3005P thermocycler (Agilent Technologies, Santa Clara, USA). The qRT-PCR mixture contained $2 \mu \mathrm{l}$ of cDNA template, $10 \mu \mathrm{l}$ of SYBR Green Real-Time PCR Master Mix (TOYOBO, Tokyo, Japan), $7 \mu$ of DEPC water, and $1 \mu \mathrm{l}$ of each gene-specific primer. The PCR program was 1 cycle at $95^{\circ} \mathrm{C}$ for $60 \mathrm{~s}, 35$ cycles of $95^{\circ} \mathrm{C}$ for $15 \mathrm{~s}, 58^{\circ} \mathrm{C} / 63^{\circ} \mathrm{C}$ for $40 \mathrm{~s}$, and $72^{\circ} \mathrm{C}$ for $40 \mathrm{~s}, 95^{\circ} \mathrm{C}$ for $60 \mathrm{~s}, 58^{\circ} \mathrm{C} / 63^{\circ} \mathrm{C}$ for $15 \mathrm{~s}$, and $72{ }^{\circ} \mathrm{C}$ for $30 \mathrm{~s}$. The melting curve analysis was performed by 1 cycle at $95{ }^{\circ} \mathrm{C}$ for $60 \mathrm{~s}, 58^{\circ} \mathrm{C} / 63{ }^{\circ} \mathrm{C}$ for $15 \mathrm{~s}$, and $72{ }^{\circ} \mathrm{C}$ for $30 \mathrm{~s}$, starting at $58{ }^{\circ} \mathrm{C}$ with a heating rate of $0.2{ }^{\circ} \mathrm{C}$ per second up to $95{ }^{\circ} \mathrm{C}$. The cycle threshold $\left(C_{\mathrm{T}}\right)$ values for each gene were averaged. The following nutrient transporters were investigated in our study: solute carrier (SLC) family 1 member 2 (EAAT2), SLC family 1 member 1 (EAAT3), SLC family 7 member 1 (CAT1), SLC family 7 member 2 (CAT2), SLC family 7 member $6\left(y^{+} L A T 2\right)$, SLC family 7 member $9\left(b^{0,+} A T\right)$, SLC family 7 member $5(L A T 1)$, SLC family 43 member 2 (LAT4), SLC family 38 member 1 (SNAT1), SLC family 38 member 2 (SNAT2), SLC family 15 member 1 (PepT1), SLC family 9 member 2 (NHE2), and SLC family 9 member 3 (NHE3). Six housekeeping genes, $\alpha$-tubulin, glyceraldehyde-3-phosphate dehydrogenase (GAPDH), $\beta$-actin, TATA box binding protein (TBP), ribosomal protein L13 (RPL13), and hypoxanthine phosphoribosyltransferase $1(H P R T 1)$ were also evaluated. All the gene-specific primers were designed by Primer Premier 5.0 software (Premier Biosoft, Palo Alto, CA, USA). Table 1 shows the primer sequences used.

\subsection{Statistical analysis}

The relative weight of embryo was absolute embryo weight to set egg weight, and the relative weight of organs (head, brain, heart, liver, gizzard, small intestine, kidney, lung, leg, and thorax) was measured by the absolute organ weight to set yolkfree embryo weight.

The obtained $C_{\mathrm{T}}$ values of housekeeping genes were quantified and entered into the geNorm application according to the method described by Vandesompele et al. (2002). The average expression stability $(\mathrm{M})$ values of control genes calculated by geNorm showed that $G A P D H$, and $\beta$-actin, TBP, and HPRT1 were the most stable genes among GAPDH, $\beta$-actin, HPRT1, TBP, RPL13, and $\alpha$-tubulin. In addition, the pair-wise variation value $\mathrm{V}_{4 / 5}$ was below 0.15 and the normalization factors utilized GAPDH, $\beta$-actin, TBP, and HPRT1 as housekeeping genes. The relative mRNA expression levels were calculated by the method of $2^{-\Delta C_{\mathrm{T}}}$ and revised through normalization factors. Data were processed by SAS version 9.1.3 statistical software package (SAS Institute Inc., Cary, NC, USA). The correlation coefficients (CCs) were derived from the Pearson product-moment correlation using a CORR Procedure analysis. The regression analysis was performed by the REG Procedure. A linear model, power function or logarithmic function was decided according to the scatter diagram plot, which used a least-square regression analysis method of the REG procedure by a stepwise variable filter method. Values were expressed as the mean \pm standard error (SE). Differences with $P<0.05$ and $P<0.01$ were considered statistically significant and highly significant, respectively. 
Table 1 Primers used for real-time PCR

\begin{tabular}{|c|c|c|c|}
\hline Gene & GenBank ID & Sense (S)/antisense (AS) primer $\left(5^{\prime} \rightarrow 3^{\prime}\right)$ & $\begin{array}{r}\text { PCR product } \\
\text { length (bp) } \\
\end{array}$ \\
\hline \multicolumn{4}{|c|}{ Transporter gene } \\
\hline \multirow[t]{2}{*}{$b^{0,+} A T$} & XM_005514428.1 & S: AATCATTGGCTCAGGTATCTT & 237 \\
\hline & & AS: TTTGTGACGAGTAGGCTTG & \\
\hline \multirow[t]{2}{*}{$C A T 1$} & XM_005501421 & S: CTTCGCCGTGGTGATA & 108 \\
\hline & & AS: CCGAGGACGAGGATGT & \\
\hline \multirow[t]{2}{*}{ CAT2 } & XM_005501186 & S: TCAAGCGTAGCAAGAGC & 232 \\
\hline & & AS: CGAAGATTAGGACCAAGAT & \\
\hline \multirow[t]{2}{*}{ EAAT2 } & NM_001282830.1 & S: GCCTAAACAAGTAGAAGTGC & 140 \\
\hline & & AS: CCAGGATGACACCGAATA & \\
\hline \multirow[t]{2}{*}{ EAAT3 } & XM_005507165.1 & S: ACAGGTGTTGCTGCTTTG & 171 \\
\hline & & AS: GGTGCTGCCCACTCTAT & \\
\hline \multirow[t]{2}{*}{$L A T 1$} & XM_005504728 & S: GCAAAGGGTGATGTGACGAG & 170 \\
\hline & & AS: AGAGGCAGGTTTCTGTAGGGA & \\
\hline \multirow[t]{2}{*}{ LAT4 } & XM_005502006.1 & S: GACCTTCACATCGCTTACG & 163 \\
\hline & & AS: TGCCCAGACAAGCAGAAT & \\
\hline \multirow[t]{2}{*}{ NHE2 } & XM_005504658 & S: ATTGAGCCACTCTTTGTCTT & 236 \\
\hline & & AS: TGGTTCTTCCCAACTGTAG & \\
\hline \multirow[t]{2}{*}{ NHE3 } & XM_418895.2 & S: ATTGCCTCTTTTACCCTTAC & 215 \\
\hline & & AS: CTGTCCAGGTGGCCCATTA & \\
\hline \multirow[t]{2}{*}{ PepT1 } & XM_005504628.1 & S: CTATTCAGATTCAGCCAGACC & 250 \\
\hline & & AS: ATTACTTTGATTTGGGATTGC & \\
\hline \multirow[t]{2}{*}{ SNAT1 } & XM_005499915 & S: TGGGCGGTTTCTTGTTGT & 277 \\
\hline & & AS: GATGGTGGGCAAAGCGTA & \\
\hline \multirow[t]{2}{*}{ SNAT2 } & XM_005499916 & S: GTGGCACCTTTGGTAGATG & 129 \\
\hline & & AS: AATCGCAGGATGGCAGAC & \\
\hline \multirow[t]{2}{*}{$y^{+} L A T 2$} & XM_001231336 & S: GCTGAACTTGGAACCACTATTAC & 102 \\
\hline & & AS: AAGTGAGGTCCACAAACGAA & \\
\hline \multicolumn{4}{|c|}{ Housekeeping gene } \\
\hline \multirow[t]{2}{*}{$\alpha$-tublin } & NM_001080860 & S: GAGAACACGGATGAAACCTACT & 118 \\
\hline & & AS: TGGTGGCTGACACTAAATGG & \\
\hline \multirow[t]{2}{*}{$\beta$-actin } & NM_205518.11 & S: ATTGTCCACCGCAAATGCTTC & 113 \\
\hline & & AS: AAATAAAGCCATGCCAATCTCGTC & \\
\hline \multirow[t]{2}{*}{$G A P D H$} & NM_001282835.1 & S: TCTGCCAAAGTCCAAGTG & 187 \\
\hline & & AS: ACTTTATGTTGCTGGGAT & \\
\hline \multirow[t]{2}{*}{ HPRT1 } & XM_005500563.1 & S: TACGACCTGGACTTGTTCT & 172 \\
\hline & & AS: ATTTATAGCCACCCTTGAG & \\
\hline \multirow[t]{2}{*}{ RPL13 } & XM_005504844.1 & S: TGTCCAACCATCCGATACCA & 263 \\
\hline & & AS: GTCGCCATCTTCAGTTCCTCA & \\
\hline \multirow[t]{2}{*}{$T B P$} & XM_005508625.1 & S: CAGCCCATTTACCAGG & 142 \\
\hline & & AS: CAACCAAGATTCACCGT & \\
\hline
\end{tabular}

$b^{0,+} A T$ : solute carrier (SLC) family 7 member 9; CAT1: SLC family 7 member 1; CAT2: SLC family 7 member 2; EAAT2: SLC family 1 member 2; EAAT3: SLC family 1 member 1; LAT1: SLC family 7 member 5; LAT4: SLC family 43 member 2; NHE2: SLC family 9 member 2; NHE3: SLC family 9 member 3; PepT1: SLC family 15 member 1; SNAT1: SLC family 38 member 1; SNAT2: SLC family 38 member 2; $y^{+} L A T 2$ : SLC family 7 member 6; GAPDH: glyceraldehyde 3-phosphate dehydrogenase; HPRT1: hypoxanthine phosphoribosyltransferase 1; RPL13: ribosomal protein L13; TBP: TATA box binding protein 


\section{Results}

\subsection{Growth of embryo and organs}

The absolute weight of yolk-free embryo increased from $1.27 \mathrm{~g}$ on E9 to $11.47 \mathrm{~g}$ on DOH (Fig. 1). The relative embryo weight increased significantly throughout development, with a sharp increase from E13 to E15. According to the changes of the relative weight, ten organs were classified into four groups during the embryonic developmental stage. The head and brain were classified as the first type of organs with a gradually decreasing relative weight (Fig. 2), whereas the kidney, gizzard, and leg were classified as the second type of organ with a continuously rising relative weight (Fig. 3). The heart, small intestine, and liver were classified as the third type of organ with generally increasing relative weight from E9 to DOH but a more rapid increase near the end of incubation (Fig. 4). The lung and thorax were classified as the
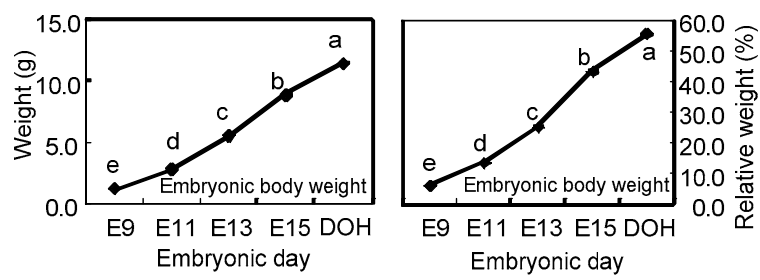

Fig. 1 Absolute weight and relative weight of embryonic body

Relative weight is calculated as absolute weight normalized to fresh egg weight (\%). Values are expressed as mean $\pm \mathrm{SE}$ $(n=20)$. Data with no common letters $(\mathrm{a}-\mathrm{e})$ indicate significant difference among embryonic days $(P<0.05)$
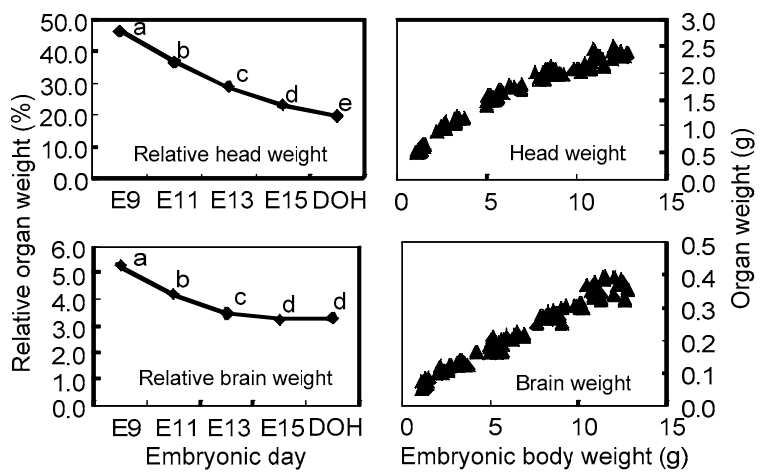

Fig. 2 Relative organ (head and brain; $n=20$ ) weight and organ (head and brain; $n=112$ ) weight plotted as a function of embryonic body weight for pigeons

Relative organ weight is calculated as absolute weight normalized to embryonic body weight without yolk (\%). Values are expressed as mean \pm SE. Data with no common letters $(\mathrm{a}-\mathrm{e})$ indicate significant difference among embryonic days $(P<0.05)$

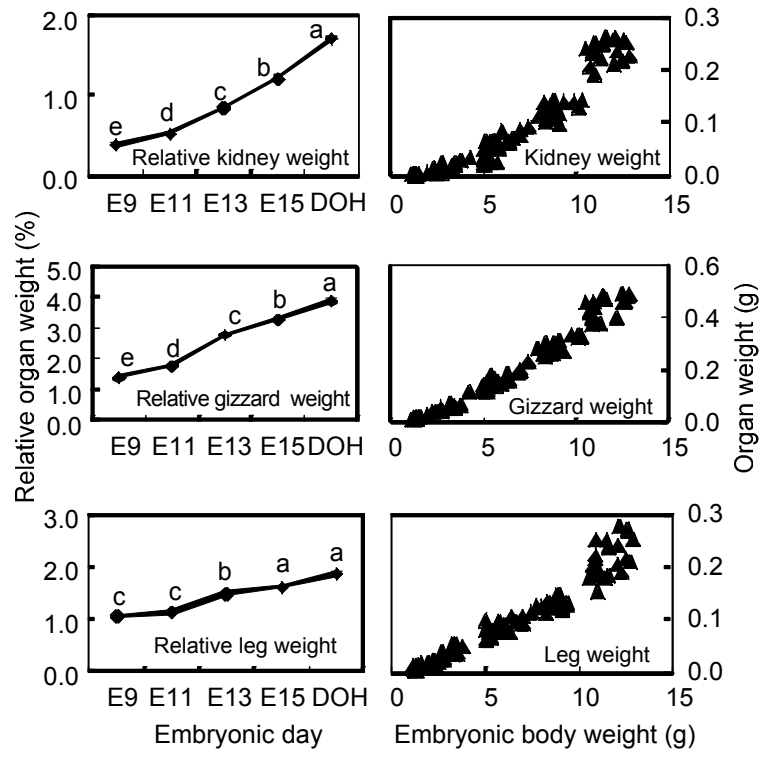

Fig. 3 Relative organ (kidney, gizzard, and leg; $n=20$ ) weights and organ (kidney, gizzard, and leg; $n=112$ ) weight plotted as a function of embryonic body weight for pigeons

Relative organ weight is calculated as absolute weight normalized to embryonic body weight without yolk (\%). Values are expressed as mean \pm SE. Data with no common letters $(\mathrm{a}-\mathrm{e})$ indicate significant difference among embryonic days $(P<0.05)$

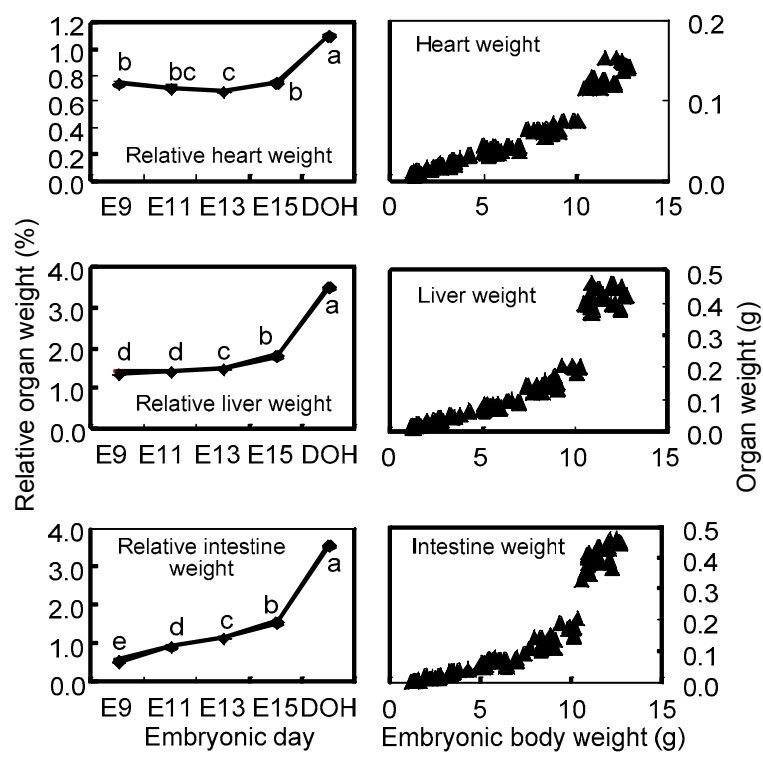

Fig. 4 Relative organ (heart, liver, and small intestine; $n=20$ ) weight and organ (heart, liver, and small intestine; $n=112$ ) weight plotted as a function of embryonic body weight for pigeons

Relative organ weight is calculated as absolute weight normalized to embryonic body weight without yolk (\%). Values are expressed as mean \pm SE. Data with no common letters $(a-e)$ indicate significant difference among embryonic days $(P<0.05)$ 
fourth type of organ with initially increasing relative weight, peaking on E11 and E13, respectively, and then decreasing (Fig. 5).

\subsection{Correlation of organ and body weight}

Correlation analysis of organ and body weight is shown in Table 2. During embryonic development, the weights of head, brain, heart, liver, lung, kidney, gizzard, small intestine, thorax, and legs were strongly positively correlated with body weight (CC $>0.8, P<0.0001)$. Yolk was negatively correlated with body weight $(\mathrm{CC}=-0.637, P<0.0001)$. In addition, we performed regression analysis on organ and body weight (Table 2).

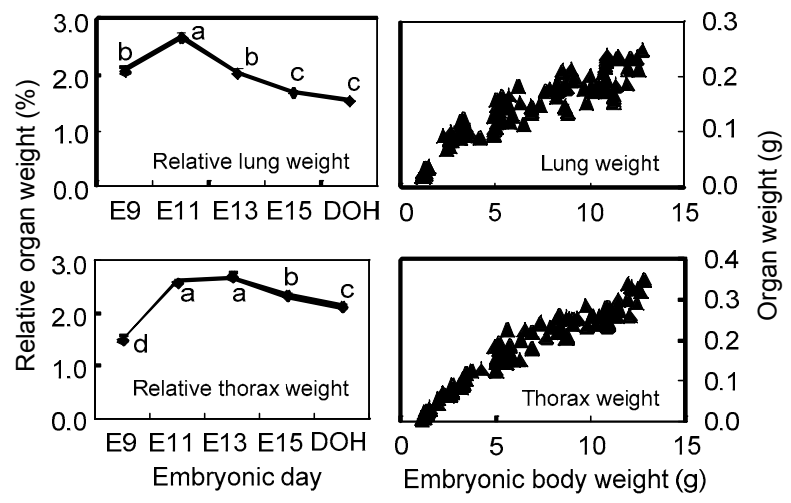

Fig. 5 Relative organ (lung and thorax; $n=20$ ) weight and organ (lung and thorax; $n=112$ ) weight plotted as a function of embryonic body weight for pigeons

Relative organ weight is calculated as absolute weight normalized to embryonic body weight without yolk (\%). Values are shown as mean \pm SE. Data with no common letters $(\mathrm{a}-\mathrm{e})$ indicate significant difference among embryonic days $(P<0.05)$
A linear model, power function or logarithmic function with organ weight was represented as a function of embryo weight according to the scatter diagram plot. The results indicated that organs have their special development patterns.

\subsection{Correlation of embryo weight and embryonic day}

On Day 16 of incubation, eggs were checked every $3 \mathrm{~h}$ to determine time of external pipping and hatching, and the DOH was on E17.5. The correlation of embryo weight and embryonic day was measured. The result showed that the body weights had linearly correlated with the embryonic day $(\mathrm{CC}=0.978$, $P<0.0001)$ and the equation of linear regression was $Y=-10.59+1.26 X\left(R^{2}=0.9606 ; Y\right.$ was embryo weight of pigeon, and $X$ was embryonic day).

\subsection{Gene expression of nutrient transporters in small intestine}

In our study, gene expressions for ten amino acid transporters (EAAT3, EAAT2, $b^{0,+} A T, y^{+} L A T 2, C A T 1$, CAT2, LAT1, LAT4, SNAT1, and SNAT2), two sodium and proton transporters (NHE2 and NHE3), and a peptide transporter (PepT1) were measured. Compared with the housekeeping genes, GAPDH, $\beta$-actin, $T B P$, and HPRT1, the nutrient transporter expression patterns were analyzed on E9, E11, E13, E15, and $\mathrm{DOH}$ in the small intestine of embryonic pigeons. The results indicated that genes of EAAT3, $b^{0,+} A T$, $y^{+}$LAT2, PepT1, LAT4, NHE2, and NHE3 showed similar expression profiles in the small intestine with

Table 2 Correlation of organ weight and embryonic body weight

\begin{tabular}{lcc}
\hline \multirow{2}{*}{ Weight of organs $(Y)$} & \multicolumn{2}{c}{ Embryonic body weight of pigeon $(X, \mathrm{~g})$} \\
\cline { 2 - 3 } & Correlation coefficient $(P$-value $)$ & Regression model $\left(R^{2}\right)$ \\
\hline Head & $0.973(<0.0001)$ & $Y=0.54 X^{0.61}(0.9874)$ \\
Brain & $0.987(<0.0001)$ & $Y=54.71 \times 10^{-3} X^{0.76}(0.9819)$ \\
Yolk & $-0.637(<0.0001)$ & $Y=1.14 \ln X(0.8164)$ \\
Thorax & $0.968(<0.0001)$ & $Y=0.19 \ln X(0.9861)$ \\
Leg & $0.971(<0.0001)$ & $Y=16.41 \times 10^{-3} X(0.9815)$ \\
Heart & $0.946(<0.0001)$ & $Y=6.27 \times 10^{-3} X^{1.13}(0.9544)$ \\
Liver & $0.903(<0.0001)$ & $Y=15.30 \times 10^{-3} \times 1.33^{X}(0.9661)$ \\
Lung & $0.925(<0.0001)$ & $Y=0.07 \ln X(0.9860)$ \\
Kidney & $0.952(<0.0001)$ & $Y=3.02 \times 10^{-3} X^{1.66}(0.9731)$ \\
Gizzard & $0.981(<0.0001)$ & $Y=12.26 \times 10^{-3} X^{1.47}(0.9920)$ \\
Small intestine & $0.894(<0.0001)$ & $Y=4.01 \times 10^{-3} X^{1.74}(0.9655)$ \\
\hline
\end{tabular}

A linear model, power function or logarithmic function with organ weight was represented as a function of embryonic body weight according to the scatter diagram plot $(n=112)$, which used a least-square regression analysis method of the REG Procedure by a stepwise variable filter method 
a gradual increase in the intestine from E9 to DOH and a rapid rise during late embryogenesis (Table 3 ). The gene expressions of CAT1, CAT2, LAT1, EAAT2, $S N A T 1$, and $S N A T 2$ exhibited similar profiles in the small intestine, with higher levels on E9 or E11, which then decreased to lower levels until the end of incubation (Table 3).

\subsection{Correlation of gene expression and weight of body and small intestine}

The results indicated that the gene expression of EAAT3 and PepT1 had a strong positive correlation with body weight $(\mathrm{CC}>0.8, P<0.0001)$, but $C A T 1$ had a strong negative correlation with body weight and it had a CC of -0.860 . The gene expressions of $b^{0,+} A T$, LAT4, NHE2, NHE3, and $y^{+} L A T 2$ showed positive correlations with body weight $(0.6<\mathrm{CC}<0.8$, $P<0.0001)$, whereas CAT2, EAAT2, SNAT1, and $S N A T 2$ had negative correlations with body weight $(-0.8<\mathrm{CC}<-0.6, P<0.0001)$. Although the LAT1 gene expression in the embryonic small intestine was not at a low level during the embryonic developmental stage, it had a low correlation with body weight $(\mathrm{CC}=$ $-0.381, P=0.0035$ ) (Table 4).

Table 3 Effect of embryonic day on gene expression of nutrient transporters in small intestine

\begin{tabular}{lccccc}
\hline \multirow{2}{*}{ Gene } & \multicolumn{5}{c}{ Gene expression $\left(\times 10^{-3}\right)$} \\
\cline { 2 - 6 } & E9 & E11 & E13 & E15 & DOH \\
\hline$b^{0,+} A T$ & $2.76 \pm 0.26^{\mathrm{b}}$ & $9.12 \pm 1.71^{\mathrm{b}}$ & $8.75 \pm 0.79^{\mathrm{b}}$ & $58.43 \pm 8.29^{\mathrm{b}}$ & $603.21 \pm 52.28^{\mathrm{a}}$ \\
CAT1 & $358.37 \pm 18.00^{\mathrm{b}}$ & $460.62 \pm 30.62^{\mathrm{a}}$ & $350.16 \pm 22.65^{\mathrm{b}}$ & $163.62 \pm 12.66^{\mathrm{c}}$ & $53.24 \pm 5.50^{\mathrm{d}}$ \\
CAT2 & $449.87 \pm 45.35^{\mathrm{b}}$ & $651.16 \pm 71.66^{\mathrm{a}}$ & $362.22 \pm 22.33^{\mathrm{b}}$ & $151.00 \pm 14.48^{\mathrm{c}}$ & $72.42 \pm 5.63^{\mathrm{c}}$ \\
EAAT2 & $403.76 \pm 48.53^{\mathrm{a}}$ & $429.48 \pm 38.33^{\mathrm{a}}$ & $374.95 \pm 32.88^{\mathrm{a}}$ & $136.05 \pm 7.77^{\mathrm{b}}$ & $67.81 \pm 4.64^{\mathrm{b}}$ \\
EAAT3 & $35.95 \pm 4.83^{\mathrm{d}}$ & $65.77 \pm 4.91^{\mathrm{d}}$ & $135.10 \pm 18.10^{\mathrm{c}}$ & $222.63 \pm 14.53^{\mathrm{b}}$ & $363.88 \pm 40.61^{\mathrm{a}}$ \\
LAT1 & $353.45 \pm 42.27^{\mathrm{a}}$ & $287.8 \pm 21.51^{\mathrm{ab}}$ & $246.56 \pm 29.82^{\mathrm{b}}$ & $148.05 \pm 17.3^{\mathrm{c}}$ & $72.71 \pm 5.44^{\mathrm{c}}$ \\
LAT4 & $52.58 \pm 2.44^{\mathrm{d}}$ & $72.76 \pm 5.15^{\mathrm{cd}}$ & $99.97 \pm 5.06^{\mathrm{bc}}$ & $121.78 \pm 13.06^{\mathrm{b}}$ & $597.92 \pm 30.59^{\mathrm{a}}$ \\
$N H E 2$ & $37.25 \pm 4.58^{\mathrm{b}}$ & $55.68 \pm 7.13^{\mathrm{b}}$ & $28.09 \pm 3.22^{\mathrm{b}}$ & $64.48 \pm 10.43^{\mathrm{b}}$ & $703.42 \pm 46.41^{\mathrm{a}}$ \\
$N H E 3$ & $22.40 \pm 3.02^{\mathrm{b}}$ & $33.43 \pm 8.71^{\mathrm{b}}$ & $25.55 \pm 2.75^{\mathrm{b}}$ & $78.89 \pm 8.66^{\mathrm{b}}$ & $420.75 \pm 58.39^{\mathrm{a}}$ \\
PepT1 & $4.96 \pm 0.70^{\mathrm{c}}$ & $4.42 \pm 0.60^{\mathrm{c}}$ & $16.96 \pm 1.22^{\mathrm{c}}$ & $88.12 \pm 6.58^{\mathrm{b}}$ & $385.96 \pm 33.79^{\mathrm{a}}$ \\
SNAT1 & $288.51 \pm 23.14^{\mathrm{a}}$ & $54.86 \pm 9.88^{\mathrm{b}}$ & $59.22 \pm 4.02^{\mathrm{b}}$ & $40.96 \pm 2.44^{\mathrm{b}}$ & $28.79 \pm 4.09^{\mathrm{b}}$ \\
SNAT2 & $851.41 \pm 56.95^{\mathrm{a}}$ & $286.70 \pm 51.87^{\mathrm{b}}$ & $185.37 \pm 6.49^{\mathrm{c}}$ & $172.85 \pm 12.02^{\mathrm{c}}$ & $153.12 \pm 8.22^{\mathrm{c}}$ \\
$y^{+}$LAT2 & $82.92 \pm 6.79^{\mathrm{c}}$ & $74.02 \pm 4.04^{\mathrm{c}}$ & $88.30 \pm 3.26^{\mathrm{c}}$ & $152.20 \pm 13.87^{\mathrm{b}}$ & $624.61 \pm 30.72^{\mathrm{a}}$ \\
\hline
\end{tabular}

E: embryonic day. GAPDH, $\beta$-actin, TBP and HPRT1 are used for normalization as housekeeping genes. Data are shown as mean \pm SE $(n=12)$. Different letters (a-e) within the same row indicate significant differences among embryonic day $(P<0.05)$

Table 4 Correlation of embryo weight and gene expression

\begin{tabular}{|c|c|c|}
\hline \multirow{2}{*}{ Gene expression $(X)$} & \multicolumn{2}{|c|}{ Embryo weight $(Y)$} \\
\hline & Correlation coefficient ( $P$-value) & Regression model $\left(R^{2}\right)$ \\
\hline$b^{0,+} A T$ & $0.743(<0.0001)$ & $Y=1.80 \ln X+12.80(0.9021)$ \\
\hline CAT1 & $-0.860(<0.0001)$ & $Y=-3.77 \ln X+0.46(0.8009)$ \\
\hline CAT2 & $-0.745(<0.0001)$ & $Y=-3.68 \ln X+1.16(0.8346)$ \\
\hline EAAT2 & $-0.790(<0.0001)$ & $Y=-4.14 \ln X-0.14(0.8372)$ \\
\hline EAAT3 & $0.820(<0.0001)$ & $Y=24.43 X^{0.78}(0.8488)$ \\
\hline LAT1 & $-0.381(0.0035)$ & \\
\hline LAT4 & $0.791(<0.0001)$ & $Y=3.91 \ln X+13.77(0.8854)$ \\
\hline PepT1 & $0.821(<0.0001)$ & $Y=1.98 \ln X+13.35(0.9585)$ \\
\hline NHE2 & $0.736(<0.0001)$ & $Y=2.47 \ln X+12.17(0.7050)$ \\
\hline NHE3 & $0.711(<0.0001)$ & $Y=2.57 \ln X+14.06(0.8279)$ \\
\hline SNAT1 & $-0.636(<0.0001)$ & $Y=9.30 \times\left(5.59 \times 10^{-3}\right)^{X}(0.8279)$ \\
\hline SNAT2 & $-0.656(<0.0001)$ & $Y=1.15 X^{-1.06}(0.8341)$ \\
\hline$y^{+} L A T 2$ & $0.782(<0.0001)$ & $Y=3.75 \ln X+13.49(0.7702)$ \\
\hline
\end{tabular}

A linear model, power function or logarithmic function with embryo weight was represented as a function of gene expression according to the scatter diagram plot $(n=60)$, which used a least-square regression analysis method of the REG Procedure by a stepwise variable filter method 
The gene expressions of $b^{0,+} A T, E A A T 3, L A T 4$, PepT1, NHE2, NHE3, and $y^{+} L A T 2$ showed positive correlations with intestinal weight $(\mathrm{CC}>0.8, P<0.0001)$, whereas $C A T 1, C A T 2$, and EAAT2 showed negative correlations, with $\mathrm{CC}$ ranging from -0.841 to -0.672 (Table 5). However, there was no significant correlation between the gene expression of other genes (LAT1, SNAT1, and SNAT2) and intestinal weight. Based on regression analysis, it was shown that different nutrient transporters had different gene expression patterns. This might be attributed to the demand of physiological function.

\section{Discussion}

\subsection{Development of embryos}

It was well known that avian embryo growth is affected by breeder age, egg weight, and incubation temperature (Tona et al., 2004; Ipek et al., 2014). With larger fresh eggs, there are more resources available within the egg's closed environment for the embryo to use during development. Thus, larger eggs have larger embryos (Al-Murrani, 1978). During embryonic development, the absolute weight of pigeon embryo increases constantly with age. The average embryo mass of pigeon on DOH was only $(13.36 \pm 0.17) \mathrm{g}$. Compared with precocial poultry, pigeons, as an altricial poultry, had small embryos for the lower energy. One report has stated that growth of embryos varies in direct proportion to egg mass during incubation (Filippi et al., 2012). However, to elucidate the changes in embryo, the relative embryo weight was measured during embryonic development. The relative embryo weight increased significantly with age, and the embryo growth in relative terms was increasing approximately up to $60 \%$ from $\mathrm{E} 9$ to $\mathrm{DOH}$. In addition, to measure the correlation of embryonic day and embryo weight, we presented the data of embryo weight as a function of embryonic day. The result showed that the growth of embryos was linearly correlated with the embryonic day, which indicated that the development of embryos was affected by embryonic day.

\subsection{Development of organs}

Different organs have different growth trajectories (Figs. 2-5). However, some organs have similar growth patterns when normalized by body weight. The head and brain, when normalized by body weight, showed a similar pattern as the first kind of organ with a gradual decrease during embryonic development (Fig. 2). It is well known that the head and the brain, among the ten organs we measured, are a section of the body renowned for dropping their relative weight during development in many species (Azzam and Mortola, 2007). The increased absolute weights of those two organs but their decreased relative weights

Table 5 Correlation of small intestinal weight and gene expression

\begin{tabular}{lcc}
\hline \multirow{2}{*}{ Gene expression $(X)$} & \multicolumn{2}{c}{ Small intestinal weight $(Y)$} \\
\cline { 2 - 3 } & Correlation coefficient $(P$-value $)$ & Regression model $\left(R^{2}\right)$ \\
\hline$b^{0,+} A T$ & $0.907(<0.0001)$ & $Y=0.07 \ln X+0.39(0.8972)$ \\
CAT1 & $-0.841(<0.0001)$ & $Y=-0.16 \ln X-0.12(0.8952)$ \\
CAT2 & $-0.672(<0.0001)$ & $Y=-0.15 \ln X-0.08(0.7738)$ \\
EAAT2 & $-0.748(<0.0001)$ & $Y=-0.17 \ln X-0.12(0.8167)$ \\
EAAT3 & $0.801(<0.0001)$ & $Y=1.10 X^{1.34}(0.8559)$ \\
LAT1 & $-0.104(0.4408)$ & \\
LAT4 & $0.943(<0.0001)$ & $Y=0.18 \ln X+0.49(0.9378)$ \\
PepT1 & $0.946(<0.0001)$ & $Y=0.92 X+0.03(0.9378)$ \\
NHE2 & $0.914(<0.0001)$ & $Y=0.11 \ln X+0.43(0.9056)$ \\
NHE3 & $0.864(<0.0001)$ & \\
SNAT1 & $-0.455(0.0004)$ & \\
SNAT2 & $-0.469(0.0003)$ & $Y=0.11 \ln X+0.45(0.8845)$ \\
$y^{+}$LAT2 & $0.942(<0.0001)$ & \\
\hline
\end{tabular}

A linear model, power function or logarithmic function with small intestinal weight was represented as a function of gene expression according to the scatter diagram plot $(n=60)$, which used a least-square regression analysis method of the REG Procedure by a stepwise variable filter method 
may be accounted for by their priority development. Li et al. (2013) and Azzam et al. (2007) observed similar growth trajectories in the head during chick embryonic development. In contrast to the head and brain, the kidney, gizzard, and leg were classified as the second kind of organ because their relative weight had similar growth patterns, initially low and increasing gradually during embryonic development. The relative weight of kidney was similar to our previous study on chicken, while the gizzard, as one of the digestive organs, showed different development trajectories as described by Li et al. (2013).

In this study, the heart, liver, and small intestine were included as the third kind of organ for the similar growth pattern with a slight increase from E9 to E15 but a rapid rise from E15 to DOH in terms of their relative weights. During embryonic development, nutrition from yolk, digestive tract or blood was stored, absorbed and transformed in the liver and then passed into other organs to utilize. However, in the final stage of incubation, $\beta$-oxidation of fatty acids cannot provide the energy needed for embryonic development (Tazawa et al., 1983; Moran, 2007). Therefore, the development of embryos was mainly driven by glucose metabolism, such as gluconeogenesis, glycogen synthesis, and glycogenolysis, which can explain the reason for the relative liver weight increasing rapidly near the end of incubation. This result demonstrated that the liver, as one organ of metabolism, might play an important role in the last 2 to $3 \mathrm{~d}$ of incubation. It is necessary to mentioned that the small intestine, as another digestive organ, plays a key role in the avian because of its key function in absorbing nutrients. In our study, both the absolute weight and relative weight of small intestine exhibited a gradual increase throughout the hatching process with a sharp rise before hatch. Similar results were also reported by Dong et al. (2012b). This change, as has also been observed in precocial poultry, such as chickens (Li et al., 2013) and turkeys (de Oliveira et al., 2009). A rapid increase in intestinal weight and relative weight from E15 to DOH was to prepare for enteral nutrition. In addition, the lung and thorax were classified as the fourth type of organ. During chick embryonic development, the formation of the vascular system of the lung was on E17, and the respiratory function of lung began close to hatching. The reasons why the development of lung showed such different patterns between precocial and altricial species required further investigation.

To test the growth pattern of organs, correlations were observed in body weight and organ weight. In addition to the yolk, ten other organs (head, brain, heart, liver, lung, kidney, gizzard, small intestine, leg, and thorax) were positively correlated with embryo body weight. When these organ weights were plotted as a function of embryonic body weight, a logarithmic, linearly or power model was used according to the scatter diagram plot. The results indicated that the ontogeny of organs was not linear with that of the embryo. Furthermore, organs had their own special growth patterns.

\subsection{Gene expression}

During the last stage of chick embryonic development, the major nutrient source for embryos not only derived from the yolk sac membrane, but also via the yolk stalk into the small intestine (Noy and Sklan, 1998). Dong et al. (2012b) had reported that nutrient absorption shifted from the sac membrane to the small intestine between E16 to DOH for pigeons. Thus, the small intestine plays a central role in nutrient absorption at the end of the incubation period. To our knowledge, the absorptive capacity of small intestine can be evaluated by studying the nutrient transporter gene expression pattern. Therefore, we investigated the gene expression of 13 nutrient transporters normally expressed in the small intestine that were responsible for nitrogen nutrient uptake. The mRNA expressions of EAAT3, $b^{0,+} A T, y^{+} L A T 2$, PepT1, LAT4, $N H E 2$, and $N H E 3$ showed similar patterns in the small intestine, with a slight increase or no change from $\mathrm{E} 9$ to $\mathrm{E} 15$ and a rapid rise from $\mathrm{E} 15$ to $\mathrm{DOH}$, suggesting an importance in the last 2 or $3 \mathrm{~d}$ before hatching. According to Hirst (1993), intestinal amino acid transporter expression is known to be induced by raised levels of dietary protein. This suggested that provision of nutrients via the yolk stalk from E16 to DOH may provide a nutrient signal for induction of transporter mRNA. On the contrary, the gene expressions of CAT1, CAT2, LAT1, EAAT2, SNAT1, and $S N A T 2$ exhibited similar profiles in the small intestine, with higher levels on E9 or E11 and lower levels toward the end of incubation; this indicated that those six genes played an important role in the second stage of incubation (from E8 to E14). 
At the brush border membrane, peptides and free amino acids are taken into cells by peptide and amino acid transporters. Reports from our laboratory on chicken suggested that $b^{0,+} A T, E A A T 3$, and PepT1, which are expressed on the brush border membrane, could be used as indicators of the small intestinal growth of chick embryos (Li et al., 2013). In this study, the mRNA levels of those three transporters increased significantly $(P<0.0001)$ with embryonic day, especially $b^{0,+} A T$, which increased approximately 220 -fold from E9 to $\mathrm{DOH}$, suggesting that $b^{0,+} A T$ was more important during late embryogenesis The $b^{0,+} A T$ is a $\mathrm{Na}^{+}$-independent amino acid transporter, with a high extracellular affinity for cationic amino acids. EAAT3, as an excitatory amino acid transporter, has a high affinity for glutamate and aspartate. Glutamate, as an oxidative fuel source, is involved in a variety of metabolic sequences in enterocytes, increasing the amounts of energy needed to meet the needs of the rapidly growing embryos. Thus, it is reasonable that mRNA expression of EAAT3 increased significantly $(P<0.0001)$ from E11 to DOH in our study. Gilbert et al. (2007) found that levels of EAAT3 mRNA increased linearly $(P=0.001)$ from E20 to D14 in broiler small intestine, and the most important site for free amino acid assimilation was the ileum. These changes suggested that EAAT3 served as an important role in the growth of the small intestine for its key function in nutrient uptake.

Amino acids are transported into the enterocyte as di- or tri-peptides through PepTl (Leibach and Ganapathy, 1996), which is more efficient then through the free amino acid transporters (Daniel, 2004). Dong et al. (2012b) stated that the mRNA levels of PepT1 increased linearly $(P<0.0001)$ from E12 to D14 in pigeon. The mRNA levels of PepT1 were greatest in the duodenum compared with the ileum, but were of middle levels in jejunum; this was consistent with studies in chicken by Gilbert et al. (2007). In this study, expression of PepT1 mRNA increased significantly from E13 to DOH, suggesting an importance in peptide transport in pigeon embryo development. In addition, the quantities of $N H E 2$ and NHE3 expressed at the brush border membrane were also evaluated in this study. The NHE2 and NHE3 belong to the family of antiporters, known generically as $\mathrm{Na}^{+} / \mathrm{H}^{+}$exchangers (NHEs). It is well known that $\mathrm{Na}^{+} / \mathrm{H}^{+}$exchange is crucial for the regulation of in- tracellular $\mathrm{H}^{+}$in exchange for external $\mathrm{Na}^{+}$. However, $\mathrm{Na}^{+} / \mathrm{H}^{+}$exchange is up- and down-regulated as a part of digestion and diarrheal diseases via intestinal neutral $\mathrm{NaCl}$ absorption (Orlowski and Grinstein, 1997). In our study, the mRNA expression of NHE2 and NHE3 increased significantly $(P<0.0001)$ on the day of hatching, which was similar to the expression of $b^{0,+} A T$ mRNA, suggesting it becomes more important in the late stage of incubation.

Gene expression of the amino acid transporters on the basolateral membrane is different from that on the brush border membrane (Gilbert et al., 2007). In our study, the genes for EAAT2, CAT1, CAT2 and LAT1 are expressed in the basolateral membrane with higher levels on E9 or E11, then decrease with age, suggesting an important role in pigeon embryonic growth. In the early stages of embryonic development, nutrients are absorbed into enterocytes from the blood through the basolateral membrane. Thus, the four genes may be expressed with higher levels on E9 or E11. It is well known that CAT proteins transport cationic amino acids in a $\mathrm{Na}^{+}$-independent way (Closs et al., 2006). However, the system $\mathrm{y}^{+}$cationic amino acid transport (CAT) family undergoes adaptive upregulation during amino acid starvation (Humphrey et al., 2006) and thus might be repressed by nutrient provision from the yolk stalk. Zeng et al. (2011) found that the level of $C A T 1$ in broiler intestine increased linearly with age $(P<0.0001)$ but changed little during embryonic development, while CAT2 mRNA increased from E9 to E17, then decreased on DOH. In our study, the CAT1 and CAT2 exhibit similar expression patterns, peaking on E11, then decreasing gradually until the end of incubation. Gilbert et al. (2007) reported similar findings in chicken, with the expressions of $C A T 1$ and $C A T 2$ decreasing with age. $L A T 1$ was investigated widely on the basis of its function to transport large neutral amino acids into Xenopus oocytes when expressed with $4 F 2 h c$ (Kanai et al., 1998; Mastroberardino et al., 1998). In our study, LAT1 expression in the intestine was at a high level on E9 and gradually decreased in expression from $\mathrm{E} 11$ to $\mathrm{DOH}$.

The sodium-coupled neutral amino acid transporter 1 (SNAT1) is a membrane protein, which plays a crucial role in the uptake of glutamine into cells in the central nervous system (Chaudhry et al., 2002). SNAT1 is also responsible for the transport of neutral 
amino acids into or out of cells in mammals (McGivan and Bungard, 2007). So far, SNAT1 is recognized as a target for oncogene action because the amount of its mRNA is increased in human hepatocarcinoma cells. In this study, the mRNA level of SNAT1 was relatively high on E9 and decreased to a low level from E11 to DOH, suggesting an important role during incubation. A similar gene expression pattern was observed in SNAT2. Our study found that the gene expression of $S N A T 2$ was greater than that of SNAT1 throughout development, which suggested that $S N A T 2$ might be more important than SNAT1 in the small intestine during embryonic development. This phenomenon can be explained by the fact that SNAT2 belongs to the system A transporter and is expressed in the intestine and most likely reflects the activity of system A (Bröer, 2008). However, SNAT2 appears adaptive upregulation during the amino acids starvation (Tanaka et al., 2005). Therefore, the gene expression of SNAT2 might be repressed by nutrient provision from the yolk stalk. Furthermore, we demonstrated that gene expression of $y^{+} L A T 2$ and LAT4 increased slowly from E9 to E15, and then increased rapidly near $\mathrm{DOH}$, suggesting an important role in the post-hatch pigeons. Similarly, the results for $y^{+} L A T 2$ were also reported in chicken to increase significantly from E18 to DOH (Gilbert et al., 2007). A similar result for $L A T 4$ was observed in chickens by Zeng et al. (2011).

To test the relationship between gene expression of nutrient transporters and embryo and small intestinal weight, we used regression analysis. Our study demonstrated that there was a strong correlation between gene expressions of EAAT3 and PepT1 and embryo weight, while there was a strong negative correlation between CAT1 gene and body weight. This suggested those three genes were more important in embryonic development. Furthermore, we found that most of those gene expressions detected in our study were strongly correlated with small intestinal weight, such as $b^{0,+} A T, y^{+} L A T 2, C A T 1, L A T 4$, EAAT3, PepT1, NHE2, and NHE3. This indicated gene expression of those nutrient transporters might facilitate the digestive capacity of the small intestine in pigeon during embryonic development. However, whether the expression of those genes can be regarded as indicators for the growth of the small intestine requires further research.

\section{Conclusions}

In our study, we classified ten organs into four types according to changes in relative weight during embryonic development. These results provide a comprehensive study of amino acid and peptide transporter mRNA in the small intestine of pigeons. Future studies will involve transporter proteins and their functionality to understand nutrient absorption capacity of small intestine in the pigeon.

\section{Compliance with ethics guidelines}

Ming-xia CHEN, Xiang-guang LI, Jun-xian YANG, Chun-qi GAO, Bin WANG, Xiu-qi WANG, and Hui-chao YAN declare that they have no conflict of interest.

All institutional and national guidelines for the care and use of laboratory animals were followed.

\section{References}

Al-Murrani, W.K., 1978. Maternal effects on embryonic and postembryonic growth in poultry. Br. Poult. Sci., 19(3): 277-281. [doi:10.1080/00071667808416476]

Azzam, M.A., Mortola, J.P., 2007. Organ growth in chicken embryos during hypoxia: implications on organ "sparing" and "catch-up growth". Respir. Physiol. Neurobiol., 159(2): 155-162. [doi:10.1016/j.resp.2007.06.003]

Bröer, S., 2008. Amino acid transport across mammalian intestinal and renal epithelia. Physiol. Rev., 88(1):249286. [doi:10.1152/physrev.00018.2006]

Chaudhry, F.A., Reimer, R.J., Edwards, R.H., 2002. The glutamine commute: take the $\mathrm{N}$ line and transfer to the A. $J$. Cell Biol., 157(3):349-355. [doi:10.1083/jcb.200201070]

Closs, E.I., Boissel, J.P., Habermeier, A., et al., 2006. Structure and function of cationic amino acid transporters (CATs). J. Membr. Biol., 213(2):67-77. [doi:10.1007/ s00232-006-0875-7]

Daniel, H., 2004. Molecular and integrative physiology of intestinal peptide transport. Annu. Rev. Physiol., 66:361384. [doi:10.1146/annurev.physiol.66.032102.144149]

de Oliveira, J.E., Druyan, S., Uni, Z., et al., 2009. Prehatch intestinal maturation of turkey embryos demonstrated through gene expression patterns. Poult. Sci., 88(12): 2600-2609. [doi:10.3382/ps.2008-00548]

Dong, X.Y., Wang, Y.M., Dai, L., et al., 2012a. Posthatch development of intestinal morphology and digestive enzyme activities in domestic pigeons (Columba livia). Poult. Sci., 91(8):1886-1892. [doi:10.3382/ps.2011-02091]

Dong, X.Y., Wang, Y.M., Yuan, C., et al., 2012b. The ontogeny of nutrient transporter and digestive enzyme gene expression in domestic pigeon (Columba livia) intestine and yolk sac membrane during pre- and posthatch development. Poult. Sci., 91(8):1974-1982. [doi:10.3382/ps. 2012-02164]

Finkler, M.S., van Orman, J.B., Sotherland, P.R., 1998. 
Experimental manipulation of egg quality in chickens: influence of albumen and yolk on the size and body composition of near-term embryos in a precocial bird. $J$. Comp. Physiol. B, 168(1):17-24. [doi:10.1007/s0036000 50116]

Filippi, L., Hironaka, M., Nomakuchi, S., 2012. Individual variation in trophic egg production: evidence for maternal manipulation in response to resource and competition levels. Ethology, 118(5):503-510. [doi:10.1111/j.14390310.2012.02039.x]

Gilbert, E.R., Li, H., Ernmersonj, D.A., et al., 2007. Developmental regulation of nutrient transporter and enzyme mRNA abundance in the small intestine of broilers. Poult. Sci., 86(8):1739-1753. [doi:10.1093/ps/86.8.1739]

Humphrey, B.D., Stephensen, C.B., Calvert, C.C., et al., 2006. Lysine deficiency and feed restriction independently alter cationic amino acid transporter expression in chickens (Gallus gallus domesticus). Comp. Biochem. Physiol. A Mol. Integr. Physiol., 143(2):218-227. [doi:10.1016/j. cbpa.2005.11.019]

Hirst, B.H., 1993. Dietary regulation of intestinal nutrient carriers. Proc. Nutr. Soc., 52(2):315-324. [doi:10.1079/ PNS19930067]

Hyde, R., Taylor, P.M., Hundal, H.S., 2003. Amino acid transporters: roles in amino acid sensing and signalling in animal cells. Biochem. J., 373(Pt 1):1-18. [doi:10.1042/ BJ20030405]

Ipek, A., Sahan, U., Baycan, S.C., et al., 2014. The effects of different eggshell temperatures on embryonic development, hatchability, chick quality, and first-week broiler. Poult. Sci., 93(2):464-472. [doi:10.3382/ps.2013-03336]

Kanai, Y., Segawa, H., Miyamoto, K.I., et al., 1998. Expression cloning and characterization of a transporter for large neutral amino acids activated by the heavy chain of 4F2 antigen (CD98). J. Biol. Chem., 273(37):23629-23632. [doi:10.1074/jbc.273.37.23629]

Leibach, F.H., Ganapathy, V., 1996. Peptide transporters in the intestine and the kidney. Annu. Rev. Nutr., 16:99-119. [doi:10.1146/annurev.nu.16.070196.000531]

Li, X.G., Yan, H.C., Zeng, P.L., et al., 2011. Comparison of difference and ontogenetic expression of EAATs mRNA in the small intestine of broiler chick embryo. Sci. Agric. Sin., 44(21):4474-4480 (in Chinese). [doi:10.3864/j.issn. 0578-1752. 2011.21.016]

Li, X.G., Yan, H.C., Zeng, P.L., et al., 2012. The ontogenetic expression of PepTl and NHEs mRNA in the small intestine of broiler embryos. Acta Agric. Boreali-Sin., 27(5):96-100 (in Chinese).

Li, X.G., Chen, X.L., Wang, X.Q., 2013. Changes in relative organ weights and intestinal transporter gene expression in embryos from White Plymouth Rock and WENS Yellow Feather Chickens. Comp. Biochem. Physiol. A Mol. Integr. Physiol., 164(2):368-375. [doi:10.1016/j. cbpa.2012.11.016]

Li, X.G., Sui, W.G., Yan, H.C., et al., 2014. The in ovo administration of L-trans pyrrolidine-2,4-dicarboxylic acid regulates small intestinal growth in chicks. Animal, 8(10):1677-1683. [doi:10.1017/S1751731114001645]

Mastroberardino, L., Spindler, B., Pfeiffer, R., et al., 1998. Amino-acid transport by heterodimers of $4 \mathrm{~F} 2 \mathrm{hc} / \mathrm{CD} 98$ and members of a permease family. Nature, 39(6699): 288-291. [doi:10.1038/26246]

McGivan, J.D., Bungard, C.I., 2007. The transport of glutamine into mammalian cells. Front. Biosci., 12:874-882. [doi:10.2741/2109]

Miska, K.B., Fetterer, R.H., Wong, E.A., 2014. The mRNA expression of amino acid transporters, aminopeptidase $\mathrm{N}$, and the di- and tri-peptide transporter PepT1 in the embryo of the domesticated chicken (Gallus gallus) shows developmental regulation. Poult. Sci., 93(9):2262-2270. [doi:10.3382/ps.2014-03983]

Moran, E.T., 2007. Nutrition of the developing embryo and hatchling. Poult. Sci., 86(5):1043-1049. [doi:10.1093/ps/ 86.5.1043]

Mott, C.R., Siegel, P.B., Webb, K.E., et al., 2008. Gene expression of nutrient transporters in the small intestine of chickens from lines divergently selected for high or low juvenile body weight. Poult. Sci., 87(11):2215-2224. [doi:10.3382/ps.2008-00101]

Noy, Y., Sklan, D., 1998. Yolk utilisation in the newly hatched poult. Br. Poult. Sci., 39(3):446-451. [doi:10.1080/00071 669889042]

Noy, Y., Uni, Z., Sklan, D., 1996. Routes of yolk utilisation in the newly-hatched chick. Br. Poult. Sci., 37(5):987-996. [doi:10.1080/00071669608417929]

Orlowski, J., Grinstein, S., 1997. $\mathrm{Na}^{+} / \mathrm{H}^{+}$exchangers of mammalian cells. J. Biol. Chem., 272(36):22373-22376. [doi:10.1074/jbc.272.36.22373]

Poncet, N., Taylor, P.M., 2013. The role of amino acid transporters in nutrition. Curr. Opin. Clin. Nutr. Metab. Care, 16(1):57-65. [doi:10.1097/MCO.0b013e32835a885c]

Speier, J.S., Yadgary, L., Uni, Z., et al., 2012. Gene expression of nutrient transporters and digestive enzymes in the yolk sac membrane and small intestine of the developing embryonic chick. Poult. Sci., 91(8):1941-1949. [doi:10. 3382/ps.2011-02092]

Stepińska, M., Mroz, E., Jankowski, J., 2012. The effect of dietary selenium source on embryonic development in turkeys. Folia Biol. (Krakow), 60(3-4):235-241. [doi:10. 3409/fb60_3-4.235-241]

Sun, X., Zhang, H., Sheikhahmadi, A., et al., 2015. Effects of heat stress on the gene expression of nutrient transporters in the jejunum of broiler chickens (Gallus gallus domesticus). Int. J. Biometeorol., 59(2):127-135. [doi:10.1007/ s00484-014-0829-1]

Tanaka, K., Yamamoto, A., Fujita, T., 2005. Functional expression and adaptive regulation of $\mathrm{Na}^{+}$-dependent neutral amino acid transporter SNAT2/ATA2 in normal human astrocytes under amino acid starved condition. Neurosci. Lett., 378(2):70-75. [doi:10.1016/j.neulet.2004. 12.030]

Tangara, M., Chen, W., Xu, J., et al., 2010. Effects of in ovo 
feeding of carbohydrates and arginine on hatchability, body weight, energy metabolism and perinatal growth in duck embryos and neonates. Br. Poult. Sci., 51(5):602608. [doi:10.1080/00071668.2010.520303]

Tazawa, H., Visschedijk, A.H., Wittmann, J., et al., 1983. Gas exchange, blood gases and acid-base status in the chick before, during and after hatching. Resp. Physiol., 53(2): 173-185. [doi:10.1016/0034-5687(83)90065-8]

Tona, K., Onagbesan, O., de Ketelaere, B., et al., 2004. Effects of age of broiler breeders and egg storage on egg quality, hatchability, chick quality, chick weight, and chick posthatch growth to forty-two days. J. Appl. Poult. Res., 13(1):10-18. [doi:10.1093/japr/13.1.10]

Vandesompele, J., de Preter, K., Pattyn, F., et al., 2002. Accurate normalization of real-time quantitative rt-per data by geometric averaging of multiple internal control genes. Genome Biol., 3(7):12. [doi:10.1186/gb-2002-3-7-research 0034]

Xie, P., Zhang, A.T., Wang, C., et al., 2012. Molecular cloning, characterization, and expression analysis of fatty acid translocase (FAT/CD36) in the pigeon (Columba livia domestica). Poult. Sci., 91(7):1670-1679. [doi:10.3382/ps. 2011-02097]

Xie, P., Liu, L.L., Wang, C., et al., 2013. Molecular cloning, characterization, and mRNA expression of intestinal fatty acid binding protein (I-FABP) in Columba livia. J. Poult. Sci., 50(1):9-19. [doi:10.2141/jpsa.0110125]

Zeng, P.L., Li, X.G., Wang, X.Q., et al., 2011. The relationship between gene expression of cationic and neutral amino acid transporters in the small intestine of chick embryos and chick breed, development, sex, and egg amino acid concentration. Poult. Sci., 90(11):2548-2556. [doi:10. 3382/ps.2011-01458]

\section{中文概要}

题 目: 家鸽胚胎的生长与其小肠营养素转运载体基因表达

目 的: 探索家鸽胚胎期器官生长发育及其小肠营养素转 运载体基因表达规律, 为家鸽胚胎期的营养调控 提供理论基础。

创新点: 第一次较全面地研究了家鸽胚胎期小肠氨基酸转 运载体基因表达规律。

方 法: 利用实时苂光定量逆转录聚合酶链反应 (real-time RT-PCR）技术，同时结合了多内标校正方法对 小肠营养素转运载体基因表达模式进行分析。

结 论: 在家鸽胚胎期发育的过程中, 不同的器官生长模 式不完全一致。营养素转运载体 $b^{0,+} A T 、 E A A T 3 、$ LAT4、PepT1、NHE2、NHE3 和 $y^{+} L A T 2$ 基因的 表达与小肠重量呈正相关关系, CAT1、CAT2 和 $E A A T 2$ 基因的表达与小肠重量呈负相关关系。

关键词: 胚胎生长; 营养素转运载体; 基因表达; 小肠; 家鸽 